\title{
La antonimia léxica en los epigramas funerarios áticos del siglo IV a. C.
}

\section{Lexical Antonymy in the Attic Funerary Epigrams from the $4^{\text {th }}$ Century B. C.}

\author{
Evelia Arteaga Conde \\ https://orcid.org/0000-0002-6562-6982 \\ Universidad Autónoma de la Ciudad de México, México \\ evelia.arteaga@uacm.edu.mx
}

Resumen: En el presente texto se analizarán diferentes clases de antonimia léxica en algunos epigramas funerarios áticos del siglo IV a. C. con el objetivo de mostrar que fue un recurso esencial en el desarrollo de un estilo propio. El análisis de estas antonimias léxicas se dividirá en dos ámbitos (sin implicar que sean los únicos que las presentan): el que destaca lo que el difunto hizo y dejó en esta vida, y el que hace énfasis en alguna cuestión del Más Allá. A través de este análisis se verá que dichas oposiciones reflejan formas de concebir la existencia y de actuar en ella.

Palabras Clave: Epigramas funerarios, antonimia léxica, Grecia clásica, oposición, vida y muerte

ABSTRACT: In this text, various kinds of lexical antonymy in some funerary epigrams from the 4th century B.C. will be analyzed with the intent of showing that this kind of opposition was an essential resource for developing their own style. The analysis of these lexical antonymies will be divided in two fields (without implying these two to be the only ones to present them): when what the deceased did and left in this life is highlighted; and when there is emphasis in some subject of the afterlife. This analysis will show that such oppositions depict ways of conceiving existence and behaving in it.

KeYwords: Funerary Epigrams, Lexical Antonymy, Classical Greece, Opposition, Life and Death

RECIBIDO: 30/06/2020 • ACEPTADO: 17/09/2020 • VERSIÓN FINAL: 7/10/2020

En Grecia, desde la época arcaica, fue importante dejar una constancia física del lugar en donde estaba enterrado el difunto, tal como aparece ya en Ho- 
mero. ${ }^{1}$ Esto se convirtió, a través de los siglos, en inscripciones funerarias en verso llamadas "epigramas", por estar grabadas en un soporte, o "epitafios", por estar sobre una tumba.

Estos epigramas funerarios desarrollaron su propio estilo: no eran lamentos propiamente dichos, ni solamente alabanzas (por ejemplo, a los caídos en combate), ni representaciones dramáticas (con diálogos), ni inscripciones dirigidas a los dioses; sino que, usando toda esa herencia, crearon un vocabulario, fórmulas y una estructura específica y original.

Este estilo debió responder principalmente a dos elementos. El primero, es el muy estrecho y limitado espacio del sepulcro, por el cual la economía verbal y el tono sentencioso fueron fundamentales en su desarrollo. Este poco espacio fue suficiente para elaborar versos de distintos tipos de métrica, el más usado fue el dístico, constituido por un hexámetro y un pentámetro. Muchas veces, los epigramas funerarios están compuestos por más de un dístico.

El segundo es el hecho de que, en la Antigüedad clásica, a menudo las tumbas se encontraban a lo largo de los caminos con la finalidad de que los caminantes las vieran y leyeran en voz alta lo que ahí decía, así que el mensaje debía ser claro y llamativo. ${ }^{2}$ Incluso muchos epigramas mencionan la figura del caminante que, en los siglos v y IV a. C., tiene varias funciones, una de las cuales es contextualizar el monumento funerario; es decir, colocarlo en un tiempo y espacio fijos o determinados. ${ }^{3}$

Entonces, a causa de estos dos elementos (el espacio tan restringido y la existencia de un destinatario específico, el caminante que lo leía), el estilo de los epigramas funerarios debió ser sencillo, natural, claro y accesible. Estas características se lograron mediante recursos retóricos, entre los que se cuenta la antonimia léxica, a partir de la cual se usan vocablos opuestos para resaltar formas de ver el mundo y de vivir cotidianamente en él.

La oposición como elemento para presentar aspectos de la realidad es un recurso retórico usado y analizado desde la Antigüedad. Según Aristóteles, Alcmeón afirmaba que "los múltiples asuntos humanos son, en realidad, dos"; ${ }^{4}$ es decir, la concepción de la realidad en pares es desarrollada desde los presocráticos. Otro ejemplo de ello es Heráclito de Éfeso, quien desa-

\footnotetext{
${ }^{1}$ Véase Hom., Od., XXIV, 80-84: “A los tres [sc. Aquiles, Patroclo y Antíloco] erigimos un túmulo grande y sin tacha, / trabajando la tropa robusta de argivos lanceros, / sobre un cabo eminente a la orilla del ancho Helesponto / por que fuese de lejos visible en el mar a los hombres / hoy en vida y a aquellos que vivan en siglos futuros" (trad. José Manuel Pabón).

${ }^{2}$ Arteaga 2019, analiza "el acto de habla" en los epigramas funerarios.

${ }^{3}$ Acerca de la figura del caminante en los epigramas funerarios, véase Tueller 2010, pp. 44ss., y Bing 2002, pp. 39-66.

${ }^{4}$ Arist., Metaph., 986a 31, trad. Tomás Calvo.
} 
rrolló una teoría de la dualidad según la cual los opuestos son complementarios.

Acerca de la "antonimia léxica", Carmen Varo explica que es "una manifestación lingüística a través de dos entidades léxicas de un principio de orden más general que opera en nuestro sistema conceptual". ${ }^{5}$ Esta autora agrega que desde Homero "hay predilección por las llamadas 'expresiones polares' o emparejamientos de términos que se contraponen, al menos, contextualmente". 6

Aristóteles es el primero en llevar a cabo, en las Categorías, un análisis de las modalidades de oposición incluidas en los distintos tipos de predicados lógicos:

De cuatro maneras se dice que una cosa se opone a otra: o bien como lo respecto a algo, o bien como los contrarios, o como privación y posesión, o como afirmación y negación. Para decirlo con un ejemplo, cada una de las cosas de este tipo se opone: como lo respecto a algo, v.g.: lo doble a la mitad; como los contrarios, v.g.: lo malo a lo bueno; como privación y posesión, v.g.: la ceguera a la vista; como afirmación y negación, v.g.: está sentado-no está sentado.7

Siglos después, en el marco de la semántica estructural, Lyons retoma esta clasificación, utiliza el concepto de "implicación" e introduce las oposiciones inversas:

1. Complementariedad: no es posible negar simultáneamente ambos términos (A implica no B y no A implica B); por ejemplo, macho / hembra.

2. Contrariedad: cumplen como condición la posibilidad de la negación de ambos elementos a la vez (A implica no B, pero no A no implica B). La característica de los opuestos de esta clase es que entre ellos existe gradación. Se consideran los antónimos propiamente dichos; por ejemplo, joven / viejo.

3. Inversión: se trata de términos que se presuponen recíprocamente (A implica B, B implica A, no A implica no B y no B implica no A); por ejemplo, padre / hijo.

Además, introduce otras relaciones de tipo espacial:

4. Oposición direccional: movimiento en una de las dos direcciones opuestas en relación a un punto dado; por ejemplo, entrar / salir, subir / bajar.

5. Relación de consecuencia: establecida entre antecedentes y consecuentes, ya sea una consecuencia positiva; por ejemplo, aprender / saber, o negativa; por ejemplo, tener / perder.

\footnotetext{
${ }^{5}$ Varo 2007, p. 11.

${ }^{6}$ Varo 2007, p. 22.

${ }^{7}$ Arist., Cat., 11b 17-23, trad. Miguel Candel.
} 
6. Oposición ortogonal: elementos perpendicularmente opuestos; por ejemplo, norte / este, norte / oeste, y la oposición antipodal, que vincula elementos diametralmente opuestos; por ejemplo, norte / sur, blanco / negro. ${ }^{8}$

Esta clasificación es la adoptada por gran parte de los manuales de semántica en uso y es la que se utilizará en el presente análisis.

Se puede afirmar que la mayoría de los epigramas funerarios áticos del siglo iv a. C. parten de opuestos. En este trabajo se analizarán algunos de los que presentan antonimias léxicas que reflejan dos ámbitos de creencias y de comportamientos cotidianos: los que resaltan cuestiones de la vida y los que usan la oposición para hablar del Más Allá. Así, a partir de este análisis, se entenderá la manera en que se establecen dichas visiones de la vida y de la muerte en esa época. Para lograr lo anterior, se seleccionaron ocho epigramas de la compilación que realizó Hansen en 1989, Carmina Epigraphica Graeca, $C E G ;{ }^{9}$ por razones de espacio, se dejará fuera su contexto físico (en muchos de ellos había estelas decoradas con imágenes).

\section{LA VIDA}

En los epigramas funerarios del siglo IV a. C. se marca especialmente la desgracia que significa fallecer cuando se es joven. Como ejemplo, se presenta el segundo dístico del siguiente epigrama, en donde se puede ver que la juventud perdida del difunto se contrapone a lo que deja en esta vida:

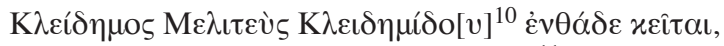

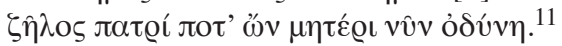

Clidemo Meliteo, hijo de Clidemides, aquí yace, siendo motivo de admiración para el padre en otro tiempo, para la madre ahora, dolor.

Las tres primeras palabras del hexámetro conforman los datos del difunto, ${ }^{12}$ posteriormente aparecen el deíctico "aquî", غ̇v $\theta \alpha ́ \delta \varepsilon$, que precisa el

\footnotetext{
${ }^{8}$ Véase Varo 2007, pp. 34-41, y Garrido 2006, pp. 697.

${ }^{9}$ Se presentará el griego transmitido por Hansen y una traducción realizada por la autora del presente texto, de las demás citas de autores griegos sólo se presenta el texto en español y se especifica el traductor.

${ }^{10}$ Como se verá, los autores de los epigramas utilizan frecuentemente la abreviación del diptongo en hiato, para que el verso se ajuste al hexámetro.

${ }^{11}$ CEG 102.

12 Así como se nombraban los hombres ciudadanos atenienses, en los epigramas funerarios se inscribía el nombre del difunto, el de su padre (patronímico) y el del demo al que pertenecía.
} 
lugar de la tumba, y el verbo "yace", xєîtal. Estos dos últimos vocablos reflejan la situación del difunto en el momento en que se leía el epigrama. ${ }^{13}$

En el pentámetro es donde se establece la oposición a través de tres anto-

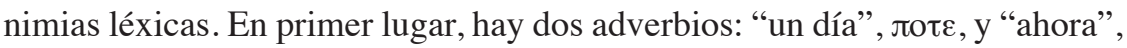
vôv, ambos elementos deícticos y antónimos de complementariedad, dado que un término implica la negación del otro. En segundo lugar, este verso

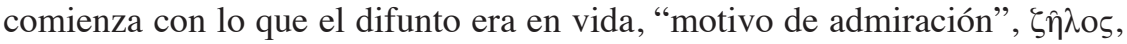
y termina con lo que causa ahora, "dolor", ódúvๆ, estos dos vocablos son antónimos léxicos de contrariedad, puesto que la admiración hacia el difunto implica no sufrir por él, pero no admirarlo no implica sufrir por él; es decir, hay una gradación entre ellos y constituyen los antónimos propiamente dichos. Finalmente, hay otra antonimia de inversión en los vocablos "padre",

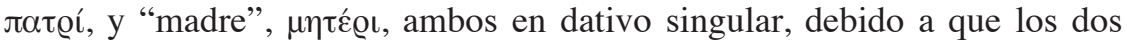
términos se presuponen recíprocamente.

Esta última oposición y el hecho de que el padre admiraba en vida al hijo y la madre sufre por su muerte recuerdan, por un lado, una de las leyes de Solón, que decía que un padre debía enseñar a su hijo un oficio o darle algún medio de soporte, así, el hijo podía cuidar de sus padres cuando éstos envejecieran. ${ }^{14}$ Quizá a eso se refiere la admiración que el padre le tenía. Por otro lado, dicha antonimia refleja lo que Lardinois y McClure afirman: "aunque el nombre de la madre frecuentemente no se registra en estos epigramas, constituye una figura genérica de lamento que provoca una piedad pública". ${ }^{15}$ De esta manera, se muestra una parte del papel del padre y de la madre en relación con los hijos (en vida y al momento de la muerte).

Así, este dístico con tres elementos de antonimia léxica opone lo que el difunto era en vida y lo que provoca después de muerto, enfatizando la desventura que, en la Grecia del siglo Iv a. C., significaba morir joven.

Otro epigrama que marca la desgracia de morir en la juventud es el siguiente dedicado a una mujer, del cual también se presenta sólo el primer dístico:

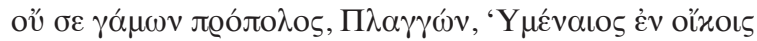

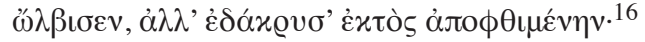

No a ti, Plangón, el sirviente de los casamientos en los hogares, Himeneo, te hizo dichosa, sino que te lloró cuando moriste fuera de ellos.

Cuando no eran ciudadanos antenienses, en ocasiones en lugar del demo se nombra su ciudad de nacimiento.

${ }^{13}$ Arteaga 2020, pp. 16-35, analiza el uso de la deixis como elemento de contextualización en los epigramas funerarios áticos clásicos.

${ }^{14}$ Véase Plu., Sol., 22.1.

${ }^{15}$ Véase Lardinois y McClure 2001, p. 185.

${ }^{16}{ }_{C E G} 587$. 
Ambos versos tienen como sujeto interpelado a la mujer difunta, Plangón. El hexámetro constituye la descripción de Himeneo (sirviente de los casamientos en los hogares) y empieza con el adverbio de negación oủ, que

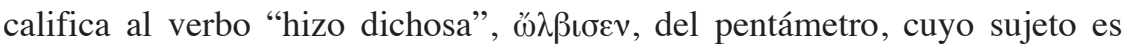
Himeneo y refiere al hecho de que la mujer no se casó. En el pentámetro, después de dicho verbo, $\omega \lambda \beta\lrcorner \sigma \varepsilon v$, está la conjunción adversativa "sino", $\dot{\alpha} \lambda \lambda \alpha$, que marca la división entre lo que Himeneo tuvo para Plangón: no la

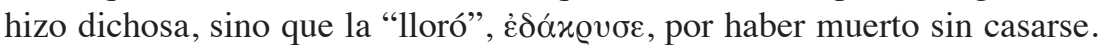

En estos versos se puede ver una antonimia léxica de complementariedad debido a que el término "hacerla dichosa" implica "no llorarla" y "no hacerla dichosa" (a través del matrimonio) implica "llorarla". Esta antonimia se refuerza con la oposición del adverbio "no", ov้, y la conjunción "sino", $\dot{\alpha} \lambda \lambda$ ' que correlacionan dichos verbos; es decir, no la hizo dichosa y, como consecuencia, la lloró. De esta manera se enfatiza la idea de que en el contexto de la creación de este epigrama funerario era un infortunio que una mujer muriera antes del matrimonio.

Estos dos ejemplos muestran una parte importante de la concepción del individuo en el siglo Iv a. C., la cual consiste en llevar a cabo ciertas acciones para tener buen renombre en la polis. Ésta es una característica que se resalta desde la época homérica; por ejemplo cuando Héctor exclama: "iQue al menos no perezca sin esfuerzo y sin gloria, sino tras una proeza cuya fama llegue a los hombres futuros!". ${ }^{17}$ Posteriormente, Isócrates (ya en los siglos v y IV a. C.) asegura que la gloria es la única inmortalidad que está en poder de los hombres: "No consientas que toda tu naturaleza sea destruida a la vez, por el contrario, ya que te tocó en suerte un cuerpo mortal, intenta dejar un recuerdo inmortal de tu espíritu". ${ }^{18}$

Los hombres atenienses de la época clásica ganaban ese reconocimiento en sus respectivas actividades y en la participación en la vida pública, como lo dice Aristóteles: "Un ciudadano, en sentido estricto, por ningún otro rasgo se define mejor que por su participación en la administración de la justicia y en el gobierno". ${ }^{19}$ Aunque no se sabe a qué se dedicaba el difunto, el padre deja implícito que su hijo estaba siguiendo las normas que marcaba la sociedad, por lo que el renombre que se estaba ganando permanecería incluso después de morir.

Acerca de las mujeres, la imagen que de ellas transmitieron los autores en época clásica fue heterogénea; por ejemplo, Pericles, en el discurso referido por Tucídides, dice: "Y si es necesario que me refiera a la virtud femenina, a propósito de las que ahora vivirán en la viudez, lo expresaré todo con un

\footnotetext{
${ }^{17}$ Hom., Il., XXII, 304-5, trad. Emilio Crespo.

${ }^{18}$ Isoc., Ad Nic., 37-38, trad. Juan Manuel Guzmán.

${ }^{19}$ Arist., Pol., 1275a 22-23, trad. Manuela García.
} 
breve consejo: si no os mostráis inferiores a vuestra naturaleza, vuestra reputación será grande, y será grande la de aquellas cuyas virtudes o defectos anden lo menos posible en boca de los hombres". ${ }^{20}$ Por otro lado, en la tragedia, la mujer fue muchas veces representada con un papel protagónico y su imagen se radicalizó, ya que aparece o sobrevalorada o infravalorada. Un buen ejemplo son Medea y Antígona, quienes son mostradas irracionales e irrefrenables, por lo que pueden actuar tanto heroica como vergonzosamente. ${ }^{21}$

Aunque las acciones de las mujeres mostradas en la tragedia son extraordinarias, parece ser cierto que en época clásica el ideal de la mujer, contrario a lo que dice Pericles, no era permanecer en el hogar pasivamente. ${ }^{22}$ No obstante, el hecho de casarse y tener hijos era considerado de suma importancia, porque uno de sus deberes en relación con la polis (tal vez el principal) era la producción de legítimos herederos para el oíxos cuyo conjunto comprendía la ciudadanía, ya que según la legislación de Pericles (451-450 a. C.) era necesario que la madre de un ciudadano ateniense también fuera ciudadana de Atenas, tal como menciona Aristóteles: "Y al tercero después, siendo arconte Antídoto, debido al gran número de ciudadanos, decretaron, a propuesta de Pericles, que no participase de la ciudadanía el que no hubiera nacido de padre y madre ciudadanos". 23 Así, hombres y mujeres, miembros del oîxo la descendencia.

Entonces, en los dos epigramas funerarios analizados hasta aquí, uno dirigido a un hombre y otro a una mujer, morir jóvenes sin haber cumplido las expectativas que se tenía de ellos (para el hombre, trabajar en beneficio de la polis y para la mujer, casarse y tener hijos) era una gran desgracia, especialmente para la familia que les sobrevivía. Eso se señala (y resalta) con las antonimias léxicas que establecen que la muerte era el fin de la posibilidad del individuo de tener una vida útil o benéfica.

Hay epigramas que refuerzan esta idea; esto es, que resaltan lo que los hombres o las mujeres debían hacer en vida que favorecería a la polis; por ejemplo, entre los dirigidos a hombres, el siguiente, que opone el nombre del difunto a una cualidad:

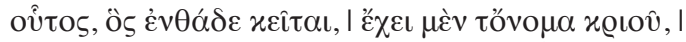

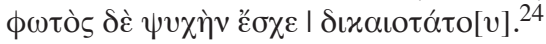

${ }^{20}$ Th., 2.45.2, trad. Juan José Torres.

${ }^{21}$ Véase A., Th., 187-191, 200-201; E., Med., 569-575.

22 Sismondo 1987, p. 409, afirma que no es en la tragedia ni en la comedia, sino en las dedicaciones individuales, en los relieves votivos, en los monumentos funerarios, en las bases de las estatuas, tal vez incluso en edificios, donde el papel de las mujeres puede ser rastreado.

${ }^{23}$ Arist., Ath., 26.4, trad. Manuela García.

${ }^{24}$ CEG 105 . 
Éste que aquí yace, tiene el nombre de "carnero", pero tenía el alma de un hombre muy justo.

El nombre propio del difunto, Kô̂os (grabado fuera del dístico), significa "carnero", es decir, un animal salvaje, y este sentido (constituyendo una metonimia) se opone a una cualidad muy civilizada. Al final del pentámetro,

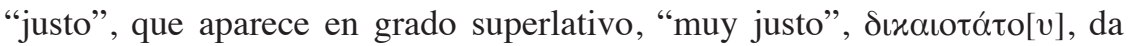
como resultado un antónimo de complementariedad, ya que un término implica la negación del otro. La mayoría de los epigramas funerarios resaltan cualidades positivas, con sustantivos o adjetivos, de los difuntos; en el caso de los dedicados a hombres, se destacan los que tienen una relación con el bienestar de la polis, por ejemplo, el ser justo. ${ }^{25}$

Acerca de las mujeres, frecuentemente se resalta si mueren en el parto, "cumpliendo" lo que se esperaba de ellas: ser madres; por ejemplo, el siguiente epigrama del cual se presenta el primer dístico:

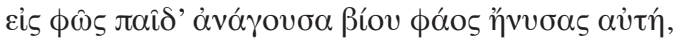

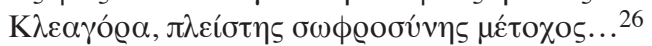

Conduciendo a la luz a un niño, perdiste la luz de la vida, Cleágora, partícipe de muchísima prudencia...

En el hexámetro se utiliza la misma palabra, "luz", en su forma ática, $\phi \hat{\omega} \varsigma$, y en su forma jónica, $\phi \alpha ́ o \varsigma$, como una metáfora: en la primera parte del verso se habla del parto de la mujer, a través del cual "condujo hacia la luz", عiऽ $\phi \hat{\omega} \varsigma$, a un niño; y en la segunda parte, de la "luz de la vida", ßíov фóos, que ella perdió en dicho parto. Así que el mismo vocablo, usado metafóricamente, constituye una antonimia léxica de complementariedad, ya que la vida implica la negación de la muerte y la no vida implica la muerte. ${ }^{27}$

Como se ve, en este epigrama en que se habla de una mujer muerta en el parto se resalta, por medio de la antonimia léxica, que ella logró parir a un niño, aunque murió en el proceso. ${ }^{28}$ Nancy Demand expone que las mujeres griegas se enfrentaban a muchos riesgos al momento del parto y,

${ }^{25}$ Véase Arteaga 2017, pp. 78-81.

${ }^{26}{ }_{C E G} 604$.

${ }^{27}$ Tsagalis 2008 , pp. 68-70, analiza esta metáfora en el contexto del monumento funerario.

28 Iriarte 2009, p. 20, menciona que el término $\lambda$ ó 0 os se refiere al mismo tiempo a la "emboscada bélica", a la "tropa en armas" y al "parto". Asimismo, explica que el término лóvos para designar el dolor del parto subraya la asimilación griega entre "dar a luz" y "luchar", pues es denominación del sufrimiento y, también, el nombre de la hazaña, de la proeza conseguida con doloroso esfuerzo. 
como consecuencia, muchas morían en él. ${ }^{29}$ Seguramente debido a esto, Medea, en Eurípides, afirma: "Preferiría tres veces estar a pie firme con un escudo, que dar a luz una sola vez". ${ }^{30}$ Por ello, se consideró que esta causa de muerte debía quedar grabada en el epitafio de Cleágora para que se viera públicamente.

Entonces, en los epigramas de los hombres y las mujeres que morían jóvenes, se resalta a través de antonimias léxicas lo que ellos eran o hacían en vida y lo que dejaron de hacer al morir. Como ya se mencionó, la razón de resaltar esto es que, en Atenas, se esperaba que las personas fueran benéficas o útiles para la polis: el hombre debía tener cualidades adecuadas para la vida en sociedad; ${ }^{31}$ y la mujer debía casarse, tener hijos, educarlos los primeros años y encargarse de la casa. ${ }^{32}$ Esto definitivamente constituye una forma particular de ver el mundo y actuar en él cotidianamente.

\section{LA MUerte y el MÁs Allá}

En algunos epigramas funerarios se habla no sólo de esta vida, sino también del Más Allá. Uno de los elementos que se oponen a la existencia terrenal es

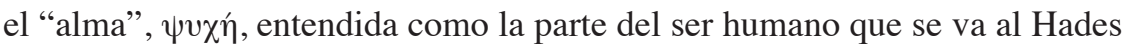
al momento de la muerte; ${ }^{33}$ por ejemplo, en el siguiente epigrama, del que sólo se presenta el primer dístico:

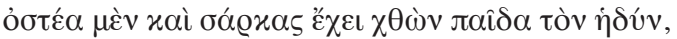

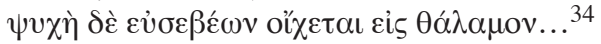

Los huesos y las carnes del dulce niño, el suelo contiene, pero el alma de los piadosos va hacia el tálamo (de Perséfone)...

En estos versos se habla de dos elementos que conforman al niño fallecido: en la primera parte del hexámetro se menciona el cuerpo físico: "huesos

${ }^{29}$ Demand 1994, pp. 71-86, analiza causas de la muerte en el parto, por ejemplo, infecciones puerperales, malaria y tuberculosis.

${ }^{30}$ E., Med., 248-251, trad. Alberto Medina.

${ }^{31}$ Austin y Vidal-Naquet 1972, p. 95 afirman: "En Atenas se es ciudadano y se participa ecuánimemente en el Estado o no se es y por consiguiente se es extraño a la comunidad política, lo mismo si se es libre (extranjero o meteco) que si se es esclavo".

32 Jenofonte dice que la producción de hijos era la primera y básica aportación común de marido y mujer al oikos (X., Oec., 7, 10-13). Para los trabajos de las mujeres en el hogar véase Mirón 2007, pp. 276-277.

${ }^{33}$ Bremmer (2002, p. 60) afirma que "es el alma libre en la forma de la psiqué la que se identifica con el alma de los muertos [...] La psiqué abandona el cuerpo en el momento de la muerte y comienza una vida ultraterrena" (trad. Menchú Gutiérrez).

${ }^{34}$ CEG 545. 


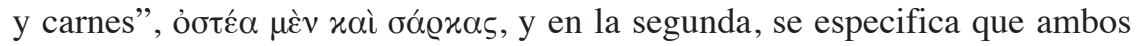
elementos se quedan sepultados en el "suelo", $\chi \theta \omega$ vv. ${ }^{35}$

Por su lado, el pentámetro presenta la misma disposición: al inicio se menciona el "alma" del niño, $\psi v \chi \eta ́$, se especifica que forma parte "de los

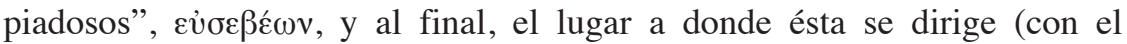
verbo oíxєtal en tiempo presente remarcando el aspecto de continuidad). Este lugar está representado (a través de una metonimia) por el "tálamo", $\theta \alpha ́ \lambda \alpha \mu$ ov, el cual se refiere al lugar "de Perséfone", diosa del inframundo, el Hades, con base en otros epigramas que sí lo mencionan específicamente. ${ }^{36}$

Así, hay una oposición entre los elementos que se piensa conforman al niño, "huesos, carnes" y "alma". Si consideramos ambos elementos como partes inseparables del individuo en vida, dicha oposición constituiría una antonimia léxica de inversión, ya que uno presupondría al otro. Esta antonimia se refuerza con los lugares "receptores" de esas dos partes: "el suelo",

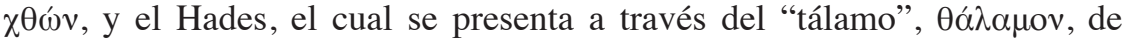
Perséfone.

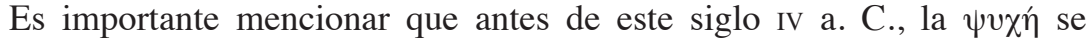
concebía como parte de la persona viva en tiempos de crisis; por ejemplo, en la Ilíada, cuando la embajada de la armada griega suplica a Aquiles que reprima su furia y detenga su lucha, éste se lamenta de que está arriesgando su $\psi v \chi \eta ́$ constantemente. ${ }^{37}$ Miller especifica que los griegos tenían una compleja visión de la persona, a la cual las agudas categorías filosóficas no se habían todavía aplicado. ${ }^{38}$

La concepción de separación entre cuerpo y alma, y la correspondiente inmortalidad de la última, fue desarrollada especialmente por los misterios griegos (orfismo, dionisismo, pitagorismo y los eleusinos) desde el siglo vI a. C. y, como menciona González, apenas en el siglo iv se empieza a ver reflejada en la epigrafía privada. ${ }^{39} \mathrm{El}$ epigrama que ahora se analiza se podría considerar como uno de los primeros ejemplos, cuyos elementos analizaremos más adelante.

El alma separada del cuerpo, y además con la especificación de ser "inmortal", aparece también en el siguiente epigrama, del que sólo se presenta un dístico:

\footnotetext{
${ }^{35}$ XӨஸ́v se traduce como "suelo" para diferenciarlo de "tierra", $\gamma \alpha i ̂ \alpha$.

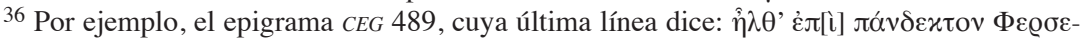
$\phi o ́ v \eta \varsigma$ $\theta \alpha \dot{\alpha} \lambda<\alpha>\mu$ ov. "[Glaucíades] llegó al tálamo de Perséfone que a todos acepta"; o el $C E G$

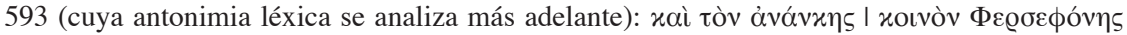

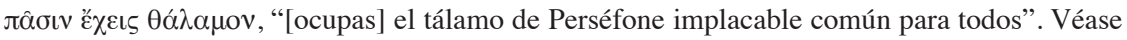
Tsagalis 2008, p. 86.

${ }^{37}$ Hom., Il., IX, 322.

${ }^{38}$ Miller 1999, p. 197.

${ }^{39}$ González 2014, p. 93.
} 


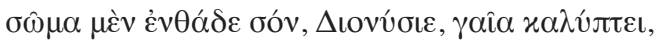

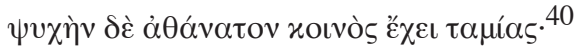

Tu cuerpo aquí, Dionisio, la tierra cubre, pero tu alma inmortal, el árbitro común tiene.

El hexámetro empieza con el sustantivo "cuerpo", $\sigma \hat{\omega} \mu \alpha$, seguido de la par-

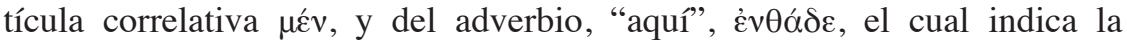
tumba, específicamente, la "tierra", $\gamma \alpha i ̂$. En el pentámetro, está el vocablo "alma", $\psi v \chi \eta$, seguido de la segunda partícula correlativa, $\delta \varepsilon ́$, y del adjetivo "inmortal", $\alpha \theta \alpha ́ v \alpha \tau o v, y$ en la segunda parte se menciona un "árbitro

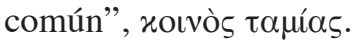

Así que este epigrama presenta dos oposiciones: la primera entre "cuer-

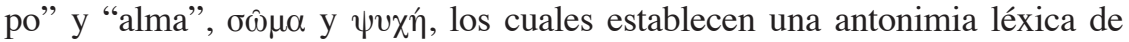
inversión (como en el epigrama anterior) ${ }^{41}$ y la segunda, entre la idea de presente mortal concreto (a través de "aquî" y de "tierra") y la de un futuro post mortem (a través de "inmortal" y de "árbitro común"), que podría constituir una antonimia de complementariedad ya que la aserción de uno implica la negación del otro (no se puede "estar" en ambos al mismo tiempo).

Si bien, como ya se mencionó, la idea de la separación del alma y el cuerpo al momento de la muerte (lo cual implicaría una inmortalidad del alma) no es común en los epigramas fuerarios de este siglo IV a. C., hay algunos elementos que indican que esta concepción (venida de los misterios griegos) se ve reflejada ya en algunos epigramas, como éste y el anterior.

El primer elemento es la mención de que el alma del individuo, al morir, va al lugar de Perséfone (al tálamo). La historia de Perséfone está narrada en el Himno homérico II, dedicado a su madre, Deméter; en éste se cuenta cómo la primera se vuelve soberana del inframundo después de que Hades la rapta, la lleva consigo y la engaña para que coma grano de granada, por lo que debe habitar en las profundidades de la tierra la tercera parte de cada año, y las otras dos, en el Olimpo. Perséfone, entonces, está relacionada tanto con la fertilidad y la abundancia (por ser hija de Deméter) como con

40 CEG 593.

${ }^{41}$ Tsagalis 2008, p. 125, menciona que "la referencia a un alma inmortal es común en los

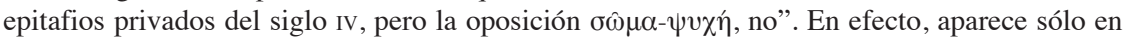
pocos epigramas (CEG 479, 549, 551 y 611). Dicho autor trae a la memoria, como ejemplo de este desarrollo, el epitafio de Platón (348 / 347 a. C.) por Espeusipo en donde aparece esta

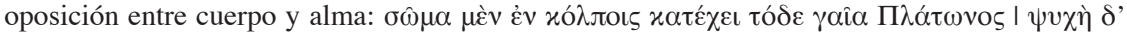

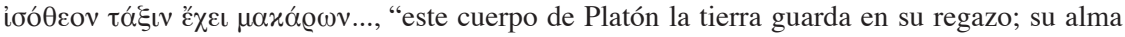
igual a los dioses, tiene un lugar entre los dichosos" (trad. propia). Por su parte, González (2014, p. 90) afirma que en este siglo iv a. C., la idea del alma inmortal que se separa del cuerpo está apenas desarrollándose. 
el inframundo (por ser consorte de Hades), por lo que no es extraño que aparezca mencionada en estos epitafios.

El "tálamo de Perséfone", explica Tsagalis, es una metáfora bien establecida en Eurípides; y durante el siglo IV esto se volvió un motivo común en los epigramas funerarios áticos. ${ }^{42} \mathrm{La}$ influencia de los Grandes Misterios en Eleusis debió ser un factor determinante que explica el amplio y sistemático uso de esta metáfora en los epigramas sepulcrales. ${ }^{43}$ Por otra parte, en algunas laminillas de oro (de ámbito órfico según Jiménez y Bernabé, ${ }^{44}$ datadas en su mayoría en los siglos IV y III a. C.) encontradas dentro de distintas tumbas, se explica que el alma del difunto debe dirigirse específicamente a Perséfone en el Más Allá, ya que ella es la que decidirá el destino de ésta:

Acabas de morir y acabas de nacer, tres veces venturoso, en este día.

Di a Perséfone que el propio Baco te liberó.

Ahora vengo como suplicante junto a la casta Perséfone por ver si me envía a la morada de los límpidos. ${ }^{45}$

Perséfone tiene un lugar especial en el orfismo no sólo porque es la soberana del Hades, sino porque, en la cosmogonía órfica, es madre de Dioniso, dios fundamental en la existencia de los seres humanos porque éstos fueron creados de las cenizas de los Titanes fulminados por Zeus en castigo por haber devorado a Dioniso. Además, como explica Alberto Bernabé, este dios y Perséfone tienen una relación con la salvación humana: Dioniso porque, gracias al mito de los Titanes, una parte de él sobrevive en los seres humanos, por ello éstos se identifican con él; y Perséfone, como soberana del Hades, quien controla el acceso al prado de los bienaventurados, porque ante ella llegan los iniciados como suplicantes y dirigen sus declaraciones de pureza y liberación. ${ }^{46}$

El segundo elemento que relaciona los dos epigramas ahora analizados que separan "cuerpo" y "alma" con los misterios es el hecho de reconocer un destino individual post mortem. Las ideas de un destino específico dependiendo del comportamiento en vida aparecen en citas relacionadas con Orfeo; por ejemplo, a Platón no parece agradarle la existencia de un banquete eterno después de la muerte, como lo menciona en la República:

Museo y su hijo [Orfeo], por su parte, conceden a los justos, de parte de los dioses, bienes más resplandecientes que los de Homero y Hesíodo. Según lo que se narra,

\footnotetext{
42 Véase Supp., v. 1022.

${ }^{43}$ Véase Tsagalis 2008, p. 95.

44 Bernabé y Jiménez 2002, pp. 231-242.

${ }^{45}$ L 7 y L 10a.6-7, trad. Alberto Bernabé y Ana Isabel Jiménez 2002.

${ }^{46}$ Véase Bernabé 2010,p. 437.
} 
en efecto, los llevan al Hades, coronadas sus cabezas, les preparan un banquete de santos y les hacen pasar todo el tiempo embriagados, con el pensamiento de que la retribución más bella de la virtud es una borrachera eterna. ${ }^{47}$

El tercer elemento, estrechamente relacionado con el anterior, es la

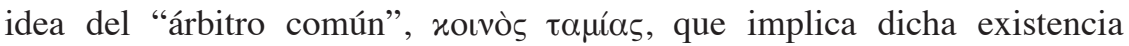
individualizada después de la muerte, la cual es juzgada dependiendo del comportamiento en vida. ${ }^{48}$ Platón, en el Gorgias, habla de unos jueces (Minos, Radamantis y Éaco) que dictan sentencia al alma de los muertos y afirma: "La muerte, según yo creo, no es más que la separación de dos cosas, el alma y el cuerpo. Cuando se han separado la una de la otra, conserva cada una de ellas, en cierto modo, el mismo estado que cuando el hombre estaba en vida". 49 Y en el Crátilo atribuye esta idea a los órficos: "En efecto, hay quienes dicen que [el cuerpo] es la 'tumba' del alma, como si ésta estuviera enterrada en la actualidad [...] Sin embargo, creo que fueron Orfeo y los suyos quienes pusieron este nombre, sobre todo en la idea de que el alma expía y de que tiene al cuerpo como recinto en el que 'resguardarse' bajo la forma de prisión". 50

La idea de que el cuerpo era la tumba del alma provenía de la concepción órfica, ya mencionada, del crimen cometido por los Titanes al matar a Dioniso, ya que - según esta concepción - los seres humanos fueron creados a partir de la ceniza de éstos mezclada con la tierra; por eso los seres humanos tienen una parte inmortal, el alma, venida de los dioses, y otra mortal, el cuerpo, procedente de la tierra.

Elvira Gangutia, en su estudio sobre semántica estructural, explica el

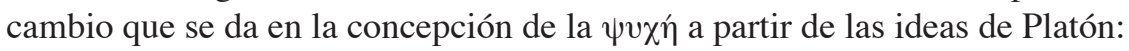

$\sigma \hat{\omega} \mu \alpha$ en Homero era "hombre o animal muerto" y luego al borrarse la distinción con $\delta \varepsilon ́ \mu \alpha \varsigma$ "cuerpo vivo" ocupa también su lugar, se opone como "cuerpo en

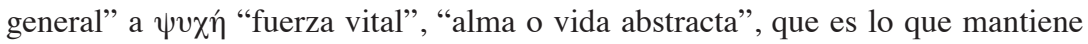
vivo el cuerpo. Al crecer desmesuradamente el plano de la "vida en general" hasta

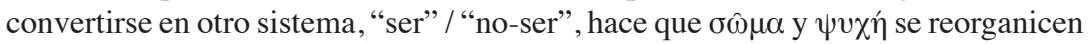
sobre estos nuevos planos..$^{51}$

Entonces, los misterios griegos, especialmente el orfismo, y posteriormente Platón, plantean la idea de una inmortalidad del alma que se separa del cuerpo al momento de la muerte; y hay algunos epigramas funerarios del

\footnotetext{
${ }^{47}$ Pl., $R ., 363$ c.2-d.2, trad. Conrado Eggers.

${ }^{48}$ Tsagalis 2008, p. 125 rastrea el término $\tau \alpha \mu$ ías y lo relaciona con la escatología órfica.

${ }^{49}$ Pl., Grg., 524b 2-6, trad. J. Calonge.

${ }^{50} \mathrm{Pl}$., Cra., 400c, trad. José Luis Calvo.

${ }^{51}$ Gangutia 1977, p. 184.
} 
siglo IV a. C. que retoman esta idea expresándola por medio de antonimias léxicas, como en los dos anteriores y en el siguiente:

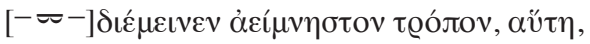

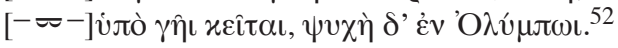

... mantuvo un carácter digno de eterna memoria, ésta;

...yace bajo tierra, pero su alma en $\approx$ el Olimpo.

Desde tiempos homéricos, el monte Olimpo es considerado el lugar donde habitan los dioses, ${ }^{53}$ así que el decir que el alma del difunto está ahí, podría implicar, a través de una metáfora (dado que los mortales no podían acceder a dicho lugar), una inmortalidad del alma. Esto constituye una antonimia léxica de oposición direccional que se expresa a través de los lugares: "bajo tierra",

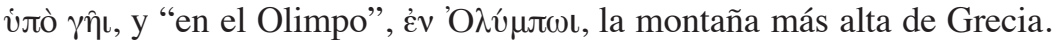

Cabe mencionar que en este epigrama no aparece el sustantivo $\sigma \omega \hat{\mu} \alpha$

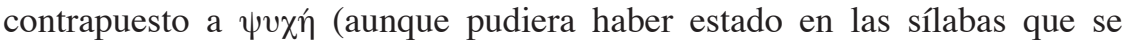
perdieron), pero se utiliza el pronombre demostrativo que hace referencia a la mujer difunta usado de forma deíctica, "ésta”, aưtๆ, al final del hexámetro, el cual se opone a la mención, al final del pentámetro, del Olimpo. Esto hace pensar en dicha posibilidad de inmortalidad del alma de la mujer difunta.

Finalmente, en el siguiente epigrama también se menciona que el alma se separa del cuerpo post mortem:

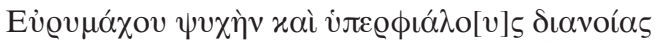

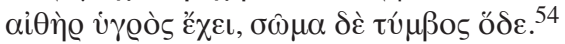

De Eurímaco, el alma y los poderosos pensamientos el éter húmedo tiene; y esta tumba, su cuerpo.

Este dístico utiliza ambos versos para la construcción de la oposición. En el hexámetro se habla de lo abstracto del difunto, "el alma", $\psi v \chi \eta ́ v$, y "los pensamientos", dıavoías; estas dos palabras constituyen el final de ambas partes del verso y están divididas por la conjunción copulativa xaí; la primera se completa con el nombre del difunto y la segunda con un

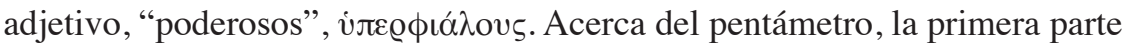
completa la idea del hexámetro al especificar que ambos, el alma y los pensamientos, están en el "éter húmedo", aî̀̀ v̀r@òs; y sólo la última parte

\footnotetext{
52 CEG 558.

${ }^{53}$ Véase Hom., Od., VI, 41-46.

${ }^{54}$ CEG 535 .
} 
de este verso habla de lo terrenal, el "cuerpo", $\sigma \hat{\mu} \mu \alpha$, que se queda en "esta

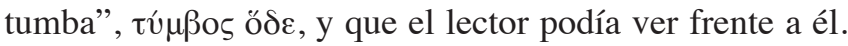

En este dístico hay dos oposiciones: la primera se establece entre

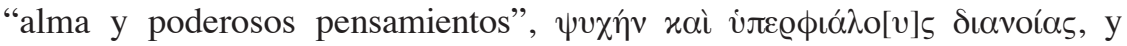
"cuerpo", $\sigma \hat{\mu} \mu \alpha$, constituyendo una antonimia léxica de inversión (como en los dos epigramas anteriores), ya que la concepción separada implica el reconocimiento y la presuposición de un elemento a partir del otro. Y la

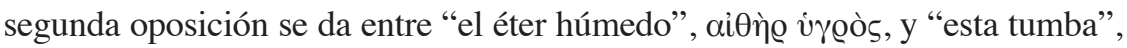

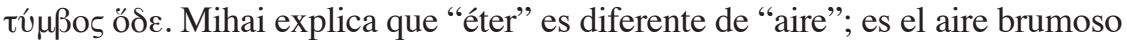
o vaporoso, la parte más baja del aire que se extiende desde la tierra hacia arriba e incluye las nubes. Si tomamos en cuenta esta definición, esta segunda contraposición podría constituir una antonimia léxica de oposición direccional (el éter arriba y la tumba abajo), tal como la que constituían la "tierra" y el "Olimpo". 55

Acerca del éter, Eurípides, en Electra, habla de éste como si fuera el lugar en donde están los muertos: “...y suelto al gran éter lamentos por mi padre" ${ }^{56}$ Rohde explica que cuando Eurípides dice que el éter, el luminoso espacio aéreo que se alza por encima de las nubes, es la residencia de las almas de los muertos, parece dejarse guiar por la idea de que las almas, después de la muerte, ya libres, van a parar a la morada de los dioses, que ya no se sitúa en el Olimpo, sino en el cielo o, concretamente, en el éter. ${ }^{57}$ Desde Homero se menciona que Zeus vive en el éter: "¡Oh, Zeus, el más glorioso y excelso, de oscuras nubes, morador del éter!", ${ }^{58}$ posteriormente Sófocles, en Áyax, lo menciona como un lugar a donde pueden ir también los seres humanos: "¡Ojalá antes se hubiera sumergido en el amplio cielo ( $\alpha i \theta \dot{\varepsilon} \varrho \alpha)$ o en el Hades, común a todos, aquel hombre que mostró a los helenos la guerra de odiosas armas que a todos afecta!". ${ }^{59}$ Entonces, aunque no sea obvio que el éter implicó en este epigrama una inmortalidad, queda claro lo que fue importante resaltar en el dístico: la parte de Eurímaco que trasciende esta vida, la $\psi v \chi \eta{ }^{60}$

55 Mihai 2010, p. 552, explica que "éter" es diferente a "aire”; es el aire brumoso o vaporoso, la parte más baja del aire que se extiende desde la Tierra hacia arriba e incluye las nubes. Si tomamos en cuenta esta definición, la oposición entre "éter húmedo" y "esta tumba" podría constituir también una antonimia léxica de oposición direccional (el primero arriba y el segundo abajo).

${ }^{56}$ E., El., 59, trad. José Luis Calvo.

${ }^{57}$ Rohde 1948, p. 238, trad. Wenceslao Roces.

${ }^{58}$ Hom., Il., II, 412, trad. Emilio Crespo.

${ }^{59}$ S., $A i ., 1187-97$.

${ }^{60}$ González 2014, p. 90, rastrea y analiza el concepto de "éter" en testimonios arcaicos y clásicos y afirma que todavía en el siglo v a. C. su mención no implica la inmortalidad de la $\psi v \chi \eta ́$, "sólo considera, probablemente desde una perspectiva física, la imagen del último aliento". Pero en el siglo IV esto empieza a cambiar. 
Así, se puede ver que hay epigramas funerarios que ponen su énfasis en el Más Allá para lo cual dividen al difunto en partes: la que se queda enterrada, el cuerpo físico, concreto, $\sigma \hat{\mu} \mu \alpha$, y la que se desprende de éste, $\psi v \chi \eta$, y va al Hades o a algún otro lugar, implicando su inmortalidad, según ideas de los misterios griegos. Estas dos partes del individuo se establecen a través de antonimias léxicas, las cuales representan la concepción de que lo que se haga en esta vida tiene consecuencias post mortem. Esta idea de la vida y de la muerte muy seguramente estaba relacionada con el tipo de comportamiento cotidiano.

\section{CONCLUSIONES}

En los ocho epigramas funerarios analizados en este trabajo, se encontraron once antonimias léxicas; más una repetida: cinco de complementariedad, una de contrariedad, tres de inversión (una de las cuales se repite) y dos de oposición direccional.

Dichas antonimias reflejaron dos creencias o concepciones diferentes de la vida y la muerte: en un primer lugar, hay epigramas funerarios que destacan una clara división entre el mundo de los vivos y la muerte; entre lo que se pudo hacer en vida y lo que se dejó de hacer al morir. Esta concepción asume el hecho de que el individuo debe seguir ciertas normas de conducta establecidas por la sociedad, por la polis, la cual juzga y espera determinadas acciones tanto de los hombres como de las mujeres (diferentes para cada uno). Además, también se asume el hecho de que no hay nada más allá de esta vida, por lo que hay que hacer lo necesario para trascender aquí, por ejemplo, a través de labores útiles para la sociedad o participando en política, para los hombres y, en el caso de las mujeres, teniendo hijos.

En segundo lugar, otros epigramas funerarios resaltan la concepción de la existencia post mortem del alma, la cual implica la inmortalidad de ésta. Esta idea presupone que no todo termina con la muerte (como se pensaba desde Homero) y que las acciones realizadas en esta vida podrían tener consecuencias que beneficiarían o perjudicarían individualmente al alma en el Más Allá. Dichas ideas fueron reflejo de los misterios griegos que se manifestaron de manera clara, por ejemplo, en Platón, y que en este siglo IV a. C. ya estaban bien asentadas en Atenas.

El hecho de mostrar que los epigramas funerarios reflejaron diferentes creencias muestra que, si bien se desarrollaron a lo largo del tiempo algunas estructuras fijas para su creación, había también un margen de libertad que permitía revelar las ideas de quien lo mandaba hacer o incluso del difunto mismo; y la antonimia léxica, como aquí se mostró, proporcionó a los creadores una herramienta muy útil para lograrlo en un par de líneas. 


\section{BIBLIOGRAFÍA}

Fuentes antiguas

Aristóteles, Categorías. Tratados de lógica (Órganon). I, trad. Miguel Candel Sanmartín, Madrid, Gredos (Biblioteca Clásica, 51), 1982.

Aristóteles, Constitución de los atenienses / PSEUdo-Aristóteles. Económicos, trad. Manuela García Valdés, Madrid, Gredos (Biblioteca Clásica, 70), 1984.

Aristóteles, Metafísica, trad. Tomás Calvo Martínez, Madrid, Gredos (Biblioteca Clásica, 200), 1994.

Aristóteles, Política, trad. Manuela García Valdés, Madrid, Gredos (Biblioteca Clásica, 116), 1988.

Carmina epigraphica graeca, vol. 2, Saeculi Iv a. Chr. n., ed. Petrus Allanus Hansen, Berolini, De Gruyter, 1989.

Esquilo, Tragedias, trad. Bernardo Perea Morales, Madrid, Gredos (Biblioteca Clásica, 97), 1986.

Eurípides, Tragedias I (El Cíclope, Alcestis, Medea, Los Heráclidas, Hipólito, Andrómaca, Hécuba), trad. Alberto Medina González y Juan Antonio López Férez, Madrid, Gredos (Biblioteca Clásica, 4), 1991.

EuríPIDEs, Tragedias II (Suplicantes, Heracles, Ion, Las Troyanas, Electra, Ifigenia entre los tauros), trad. José Luis Calvo Martínez, Madrid, Gredos (Biblioteca Clásica, 11), 1995.

Hieros logos. Poesía órfica sobre los dioses, el alma y el Más Allá, trad. Alberto Bernabé, Madrid, Akal Clásica, 2003.

Himnos homéricos, trad. Alberto Bernabé, Madrid, Gredos (Biblioteca Clásica, 8), 1978.

Homero, Ilíada, trad., pról. y notas Emilio Crespo, Madrid, Gredos (Biblioteca Clásica, 150), 1991.

Homero, Odisea, trad. José Manuel Pabón, Madrid, Gredos (Biblioteca Clásica, 48), 2007.

Isócrates, Discursos, trad. Juan Manuel Guzmán Hermida, Madrid, Gredos (Biblioteca Clásica, 23), 1982.

Jenofonte, Recuerdos de Sócrates (Económico, Banquete, Apología de Sócrates), trad. Juan Zaragoza, Madrid, Gredos (Biblioteca Clásica, 182), 1993.

Platón, Diálogos II (Gorgias, Menéxeno, Eutidemo, Menón, Crátilo), trad. J. Calonge Ruiz et al., Madrid, Gredos (Biblioteca Clásica, 61), 1983.

Platón, Diálogos IV (República), trad. Conrado Eggers Lan, Madrid, Gredos (Biblioteca Clásica, 94), 1986.

Plutarco, Vidas paralelas II (Solón-Publícola, Temístocles-Camilo, Pericles-Fabio Máximo), trad. Aurelio Pérez Jiménez, Madrid, Gredos (Biblioteca Clásica, 215), 2008.

Sófocles, Tragedias, trad. Assela Alamillo, Madrid, Gredos (Biblioteca Clásica, 40), 1981.

Tucídides, Historia de la guerra del Peloponeso, Libros I-II, trad. Juan José Torres Esbarranch, Madrid, Gredos (Biblioteca Clásica, 149), 1990. 
Fuentes modernas

Arteaga Conde, Evelia, “Aquí y ahora: la deixis en los epitafios de la Grecia clásica", Revista de Filosofía Universidad Iberoamericana, 148, enero-junio 2020, pp. 10-39.

Arteaga Conde, Evelia, "Ciudadanía y hospitalidad en Atenas vistas a través de los epitafios”, en Hospitalidad y ciudadanía. De Platón a Benhabib, UACM / Ítaca, 2017, pp. 77-104.

Arteaga Conde, Evelia, “CCómo 'habla’ el epigrama funerario ático? Una relación entre vivos y muertos", Nova Tellus, 37/2, 2019, pp. 49-65, https://doi. org/10.19130/iifl.nt.2019.37.2.817.

Austin, M. y P. Vidal-Naquet, Economía y sociedad en la antigua Grecia, trad. Teófilo de Lozoya, Barcelona, Paidós Ibérica, 1986.

Bernabé, Alberto, "The Gods in Later Orphism", en Jan N. Bremmer and Andrew Erskine (eds.), The Gods of Ancient Greece. Identities and Transformations, Edinburgh, Edinburgh University Press, 2010.

Bernabé, Alberto y Ana Isabel JimÉnez, Instrucciones para el Más Allá. Las laminillas órficas de oro, Madrid, Ediciones Clásicas, 2002.

BING, P., "The Un-Read Muse? Inscribed Epigram and Its Readers in Antiquity", en M. A. Harder et al. (eds.), Hellenistic Epigrams, Leuven, Peeters, 2002, pp. 39-66.

Bremmer, Jan N., El concepto del alma en la antigua Grecia, trad. Menchu Gutiérrez, Madrid, Siruela, 2002.

Demand, Nancy, Birth, Death and Motherhood in Classical Greece, Baltimore and London, The John Hopkins University Press, 1994.

Gangutia Elícegui, Elvira, Vida / Muerte de Homero a Platón. Estudio de semántica estructural, Madrid, Instituto Antonio de Nebrija, 1977.

Garrido Rodríguez, Ma del Camino, "Sinonimia y antonimia: significado y sentido", Actas del XXXV Simposio Internacional de la Sociedad Española de Lingüística, León, Universidad de León, 2006, pp. 691-710.

GonzÁLEZ GonzÁLEZ, Marta, "La epigrafía funeraria y la idea de alma en Grecia antigua (CEG 482; SEG 38: 440)", en CFG ( $g$ ): Estudios griegos e indoeuropeos, 2014, 24, pp. 81-94, https://doi.org/10.5209/rev_CFCG.2014.v24.44722.

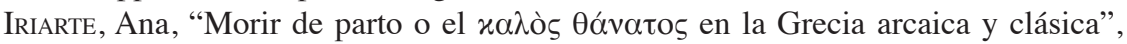
en Marco Francisco Simón et al. (eds.), Formae Mortis: El tránsito de la vida a la muerte en las sociedades antiguas, Barcelona, Universitat de Barcelona, 2009, pp. 13-24.

LARDINOIS, André y Laura MCCLURE (eds.), Making silence speak: women's voices in Greek literature and society, Princeton, University Press, 2001, http://dx.doi. org/10.1515/9780691187594.

MinAI, Adrian, "Soul's Aitherial Abode According to the Poteidaia Epitaph and the Presocratic Philosophers", Numen, 57, 2010, pp. 553-582, http://dx.doi. org/10.1163/156852710X514339.

Miller, Fred D. Jr., "Philosophical Themes in Early Greek Grave Inscriptions", en XI Congresso Internazionale di Epigrafia Greca e Latina, Roma, 18-24 (settembre 1997, Atti I), Roma, Edizioni Quazar, 1999. 
Mirón Pérez, $\mathrm{M}^{\mathrm{a}}$ Dolores, "Los trabajos de las mujeres y la economía de las unidades domésticas en la Grecia Clásica", Complutum, 18, 2007, pp. 271-280.

RoHDE, Erwin, Psique: la idea del alma y la inmortalidad entre los griegos, tr. Wenceslao Roces, México, Fondo de Cultura Económica, 1948.

Sismondo Ridgway, Brunilde, "Ancient Greek Women and Art: The Material Evidence”, American Journal of Archaeology, 91/3, jul. 1987, pp. 399-409.

Tsagalis, Christos C., Inscribing Sorrow: Fourth-Century Attic Funerary Epigrams, Berlin / New York, Walter de Gruyter, 2008, http://dx.doi.org/10.1515/9783110211658.

Tueller, Michael A., "The passer-by in archaic and classical epigram", en Manuel Baumbach et al. (eds.), Archaic and Classical Greek Epigram, Cambridge/ New York, Cambridge, Cambridge University Press, 2010, pp. 42-60.

Varo Varo, Carmen, La antonimia léxica, Madrid, Arco Libros, 2007.

Evelia Arteaga Conde es licenciada, maestra y doctora en Letras por la Universidad Nacional Autónoma de México. Desde el año 2006 es profesora investigadora de tiempo completo en la Universidad Autónoma de la Ciudad de México. Ha participado en diversos congresos nacionales e internacionales con ponencias acerca de la cultura griega arcaica y clásica, especialmente del ámbito de la muerte y de los misterios. Sus publicaciones más recientes son: en el primer semestre del año 2020, en la Revista de Filosofía de la Universidad Iberoamericana, "Aquí y ahora: la deixis en los eptiafios de la Grecia clásica”; en el año 2019, en Nova Tellus, “CCómo 'habla' el epigrama funerario ático? Una relación entre vivos y muertos"; además, en este mismo año, colaboró en Manual de adquisición de vocabulario de griego antiguo y Aproximación a las partículas griegas de la prosa ática (ambas de la Facultad de Filosofía y Letras de la UNAM). 